\title{
Exploration and Reflection on the Practical Teaching of Advertising Creative Curriculum under the Context of Information Exchange
}

\author{
ZhouPing \\ Jiujiang University, Jiujiang 332005,China
}

Keywords: Future classroom, Information interaction, Advertising creativity, Practical teaching.

\begin{abstract}
The information flow of the internet has involved in all aspects of all walks of life, and it obtains valuable information means to grasp the development opportunities. In the era of knowledge explosion, the rapid change of information contributes to knowledge update speed, the traditional forms of information transmission has been unable to meet the needs of today's social development, the emergence of the internet lies the foundation for the rapid dissemination of information, and it also slowly changes the way of getting information. At present, in the background of big data, the future of classroom teaching reform is imperative, and the future of the classroom teaching mode will gradually tend to mixed learning mode.Therefore, the advertising creative curriculum can not only pay attention to the theoretical education method, but also should creative students' thinking and strengthen students' practical ability in the theory. At the same time, we should strengthen the research and exploration of advertising creative course practical teaching and carry out the practice teaching in the background of information interaction, to guide the students to participate in the competition. From a comparative study of the self-design workshop, this paper is the establishment of a database, to further improve the advertising creative curriculum practice teaching.
\end{abstract}

\section{Introduction}

In recent years, with the development and progress of internet and computer information technology, the aspects of political, economic and social life has occurred huge change, the new era of digital media has produced subversive influence for advertising design industry and has particularly aroused the upsurge of education reform, which brings new opportunities for the reform of practice teaching mode [1-3]. Under the background of information exchange, the advertising design teaching is facing clash and confrontation of new digital media teaching mode and traditional teaching method in China, and the teaching reform has become a trend and tendency. The core of advertising design is creativity, and creativity is good or bad or not directly affect the entire advertising program delivery effect [4,5]. Therefore, the information exchange technology is closely together with improving the advertising creative course, forming a new mode of teaching practice, and it has an important influence on improving the students' aesthetic ability, broadening students horizons and stimulating students' potential awareness thinking direction [6-8]. At the same time, this paper further explores and studies the advertising creative practice teaching reform, which has a positive significance to cultivate advanced talents with market oriented society.

\section{The Development and Evolution of Information Interaction Design}

Information interactive design education is more obvious in the internet era, but also faces new development requirements. In the new media age, people can get more data information, and not need to carry out random sampling. To promote data into new productivity, information interactive brings new communication or exchange for the social activities $[9,10]$.The focus of future social advertising design will be from tangible products to focus on the relationship between information interaction design, that is the relationship between people-media-behavior-target-environment. The relationship between information interaction design elements is shown in Figure 1. 


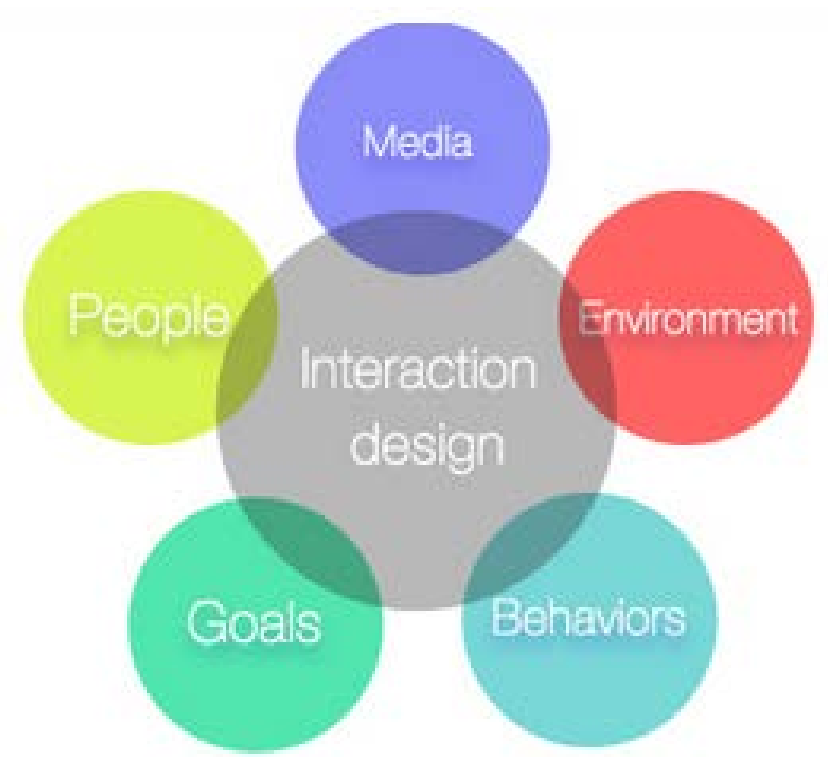

Fig. 1 The element relationship of information interaction design

Secondly, it is widely used in the internet age to make the multimedia technology and virtual reality technology, realizing the new realization form of "information-data-wisdom". In the information society, increasing the use of data information can design more abundant and successful advertising creative with the help of information exchange platform, and the perfect combination of art and advanced technology makes the two fuzzy boundaries.

\section{The Requirement Analysis of Advertising Creative Teaching Model under the New Background}

The development needs of information exchange times. In the information exchange and new media age, as the carrier of information dissemination, advertising needs to be constantly self adjustment and change. In today's society, because consumers are subject to the influence of nature, culture, time and the former state situation, they are not only the object of the information dissemination, but they begin to become the main body of information dissemination, that is the main consumption [11-13]. The new era of information dissemination environment is very different in the past the traditional communication environment, it is no longer just newspapers, television, radio, magazines, outdoor and selling points and other communication platform, but also is trigger some advertising in the network and mobile terminal widely spread through enhanced technology. In this case, the form of advertising information dissemination is no longer confined to the "one-to-many" mode, but also is the development of the "multi-to-multi" transmission mode.

In the Web3.0 era, the Internet itself has become a generic database, advertising receptors are becoming more and more personalized, and the requirements of advertising are gradually increasing. The biggest characteristic is the interactive nature in today's advertising, and the development of new media technology has changed people's use and received information form.

In the era of Internet and wireless applications, consumer behavior proposes a new AISAS theory model based on the AIDMA, and the AISAS theory model is changed from the AIDMA model. The theoretical analysis model is shown in Figure 2. 


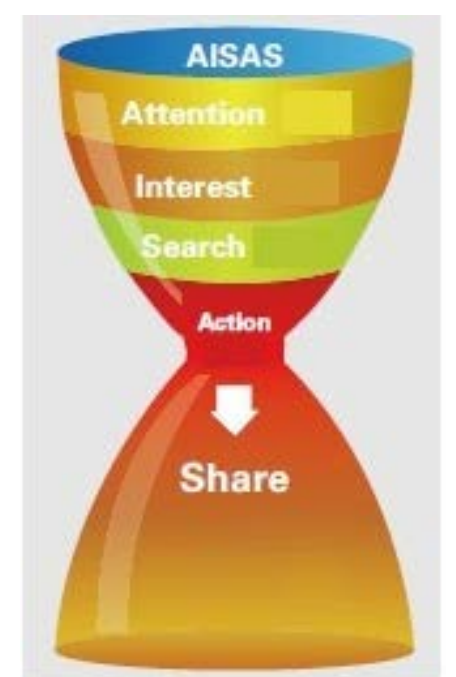

Fig. 2 AISAS theoretical analysis model

As shown in Figure 2, AISAS theory model principle is that we can through advertisements or other way to cause people attention, using the wonderful catalog and the related products cause the consumer's interest, interactive way improves the audience on the product's goodwill and recognition and using search engine tools carry out further understanding for products, stimulating the customers buy action, finally consumers as the main body of information share product information with family and friends, to increase public reputation of the product.

In the interactive information era, the unique characteristics of advertising is gradually reduced, and the integration of other popular information is becoming more and more obvious. Compared with before, today's advertising is more focused on accuracy and the rate of reception, which increases the advertising designers creative requirements [14]. Therefore, in order to improve the actual effect of advertising delivery, the information exchange technology and advertising creative teaching are closely together, forming a new practice teaching mode.

The needs of the market economy environment. The gradual transformation of the traditional newspapers, magazines and other media is the formation of a strong contrast with the rapid development of new media. With the high popularity of the Internet technology and the emergence of a wide variety of mobile terminals, people contact with the advertising media occurred great changes, and people can use leisure time to browse network information in the mobile phone that are becoming more and more popular. Therefore, we make full use of the advantages of the network platform for the advertising creative of interactive information era, and discuss the topic spread creative advertising manufacturing by mobile terminal APP, in order to better communication effects and rapid spread of speed.

From the AISAS theory model, we can know that people should contact and understand the information ways and means, consumption audience can search brand or product information through the mobile intelligent terminal app, but also can understand the product detailed information from the purchased product customer and even share shopping experience, and then obtaining information through this independent way can achieve two-way interaction. At present, many companies begin to promote their own brand through micro channel, micro-blogging or social networking sites and other new media. Therefore, the training object of the university needs to have a keen sense of smell for the market economy environment and the interactive information platform, they can design the advertisement creativity through the interactive information platform.

\section{Analysis of the Advertising Creative Course Training Direction under the Information Interactive Era}

Pay attention to theory combined with mutual awareness. At present, there are two types of opened advertising specialty colleges in China, including theoretical and design. The theory focuses on cultivating the knowledge study of students' advertisement design theory, and the design is focused on the ability of cultivating students practical design. For the design of the students, they are 
generally poorly understood theoretical knowledge of advertising design, and advertising as an independent discipline, we main research campaign history, theory, strategy, production and management. The design personnel has solid theoretical knowledge and good communication skills, and a good advertising is not just a good idea or a good creative. In the era of highly developed information technology, advertising designers must be pragmatic theories. Combined with information interactive consciousness and advertising design, people should learn to touch the psychological needs of consumers used in the heart of the bottom by advertising, but also learn to effective communication and interaction with consumers, finally people carefully sum up feedback the information and immediately improve their design.

Emphasizing the whole application, developing the innovative thinking and improving the practical ability. Advertising creativity more emphasis on the ability of develop students' creative thinking, which may be helpful to improve the ability of students' distributed thinking. But, in the information age, the students access to the broader information approach and the relatively larger number, but they easily lead to information on the fragmentation. A good advertising creative must be through the rigorous market survey, planning, evaluation, marketing and other aspects of the investigation and study. Because of the network media and other platforms, the students may only see the part of the advertising creative, and they distort the idea of advertising creative design. Therefore, we need to strengthen the students' ability on the overall design of advertising creative, and the use of the internet timely put the ads for feedback research to improve the advertising.

In the explosion of information today, everywhere is filled with all kinds of advertisements, so people have an aversion to advertising. When the design of advertising, we are going to let the ads don't like advertisements, which is the highest level of advertising design. Therefore, we want to the design of a good advertising, we must use the latest technology means, the appropriate shooting environment and rich props, which requires designers to expand their knowledge and improve their practical ability.

\section{Analysis on the Advertising Creative Curriculum Exploration Approach under the Era of Information Exchange}

Participate in the competition. In each school year, the country will regularly held various advertising events for college students, such as the national advertising technology contest, college students, OneShow young creative competition, Jingdu awards and so on. In recent years, with the continuous development of the advertising industry, the scale of the advertising competition is becoming more and more professional, and the content of the game is also more and more rich, which can be a good way to achieve the purpose of teaching and practice to promote teaching. Encouraging students participate in the competition, we not only can improve students' practical design ability, , but also allows students to clearly grasp the whole process and the latest trends of advertising creative design.

Self design workshop. In the teaching process, most of the teachers are easy to ignore the practice of the students' self design workshop. Let the students set up seminars on some research topics, they can simulate practicing practical work after the future business and mutual communicate the preliminary research and design experience of various brands design, to carry out group discussion and evaluation, so that the students not only can enhance student to understand the extent of the problem themselves, but also consolidate the achievements; the students can also learn different research design ideas and creative advertising, but also improve the students' knowledge, while expanding the surface spread of advertising design.

The establishment of the database. Because of the emergence of information interaction, all sorts of information is crazy spread, increasing greatly the amount of information. For advertising creative curriculum development, we should establish information database between teachers and students, between schools and enterprises. The database includes a variety of teaching cases and the success of the enterprise design advertising strategy plan, and we ensure that the information database involves a wide range, to facilitate the teaching of teachers better, but also can let the spare capacity of the students more learning resources. Through the establishment of the database, the school can 
absorb the enterprise complete design and analyze the pros and cons to provide a reference for the enterprise.

\section{Summary}

In the context of information exchange, the teaching reform of advertising creative curriculum has become a trend. In this paper, we need to analyze and explore the reform of creative teaching mode based on the background of information exchange, and put forward the teaching idea of combining advanced information technology and means as well as advertising creative design. This idea not only can cultivate the students' creative thinking ability, but also can exercise the students' practical ability, so that students can walk in the forefront of advertising design new technology.

\section{References}

[1] R.J. Xu. To enhance the students' historical responsibility- open a good contemporary literature history class on news professional students. News lover, 2014(2): 38-39.

[2] W.Q. Sun. Analysis of advertising professional skills training mode. News lover, 2014(2): 39-40.

[3] S.H. Hu. Research on the advertising design professional practice teaching in the market demand. Guangxi Normal University, 2014: 1-12.

[4] S.L. Wang. Research on the experimental teaching and advertising professional practice innovation ability cultivation. Journal of Hubei economy academy, 2013(4): 37-38.

[5] Y.K. Cai. Research on the advertising planning and creative course practical teaching reform. Lyceum, 2014(15):12-13.

[6] P. Zhu. Simulation, competition and actual combat- the study on the practical teaching mode of advertising creativity course. Today's media, 2014(1): 151-152.

[7] W.J. Yang. The university network ideological and political education in the perspective of human comprehensive development. Shanxi Normal University, 2014: 3-9.

[8] Fu X.Q. The design and implementation of plane advertisement creative thinking interactive teaching platform. Beijing University of Technology, 2014: 3-15.

[9] D.M. Zhu. Application of case teaching method in college advertising- the design of advertising creative and planning course teaching. Shanghai international studies university, 2013: 1-9.

[10] F.L. Dai. Research on the advertising teaching reform and innovation based on the communication theory. Jiangxi Normal University, 2014: 1-12.

[11] J.C. Chen, W.C. Lin. The exploration of course theory teaching under the background of application technology university advertising planning and creation taking advertising planning and creative course as an example. Hunan mass media vocational and technical college, 2015(4): 61-63.

[12] J.C. Xiao. Research on advertising planning and creative course teaching methods and assessment model. Journal of Chengdu University of Technology, 2014(1): 85-89.

[13] H.J. Fu. The exploration of advertising planning and creation course teaching reform under the background of digital teaching resources. Modern economic information, 2015(20): 378-379.

[14] B.Y. Zhang, Q. Zeng. The research and practice of three platform teaching mode in advertising creative and design course. Art discrimination, 2015(7): 229-230. 